\title{
Implications COVID-19 on Performance and Energy Management in the Production Electricity
}

\author{
Noor Shakir Mahmood ${ }^{1}$, Ahmed Ali Ajmi ${ }^{1}$, Shamsul Sarip ${ }^{2, *}$, Khairur Rijal Jamaludin ${ }^{2}$, \\ Hazilah Mad Kaidi ${ }^{2}$ and Hayati Abdul Talib ${ }^{2}$
}

\author{
${ }^{1}$ University of Technology, Ministry of Electricity GCEP/Middle region Baghdad, Iraq \\ ${ }^{2}$ Razak Faculty of Technology and Informatics, UTM, Kuala Lumpur, 54100, Malaysia \\ *Corresponding Author: Shamsul Sarip. Email: shamsuls.k1@utm.my \\ Received: 21 February 2021; Accepted: 06 April 2021
}

\begin{abstract}
The COVID-19 pandemic has directly impacted the electric power industry; the energy sector has experienced huge losses in electricity production. These losses have also affected the reliability of communication and employees' performance, hence destabilizing the electric power system. This article aims at achieving two objectives. First, analyzing the impact of the COVID-19 pandemic on the communication of performance (human error and human factors) and energy management in electricity production. Second, to develop a conceptual framework model to alleviate effects of the pandemic on the power sector and then improve energy management and human performance. This paper involves investigating the influence of the COVID19 pandemic on the global production of electricity in the first quarters of 2019 and 2020. A conceptual model was developed based on a case study. Additionally, to ensure reliability, a variable, namely COVID-19, was used as a moderator to examine the effects of the independent and dependent variables. The results show that scores for the internet of things (IoT) with awareness and communication (A\&C) and workplace environment management were high with Cronbach's alpha value of 0.87 for the IoT and 0.89 for A\&C. These numbers are important indicators of factors that could affect performance and energy management and should not be overlooked by the top management. The results also indicate that the pandemic has had a direct effect on the electricity production sector, and the conceptual framework model revealed that COVID-19, as a moderator, has a direct effect on the variables that significantly affect the improvement of both energy management and employee performance. The case study's results confirm the poor performance in power plant maintenance and operation, in which human error would increase especially in Iraqi power plants that have not yet adopted any internationally recognized standards for energy management. This paper contributes to the literature studying COVID-19's impact on the electricity sector in two ways: first, by developing a model to assist the electricity production sector mitigating effects of the COVID-19 pandemic, and second, by providing a detailed investigation into the pandemic's impact on the electricity sector's
\end{abstract}


global production. The findings are hoped to assist researchers and research centers in understanding the general and specific framework to manage the pandemic's effects on electricity production.

Keywords: Communication; internet of things; decision making; energy management; performance; workplace environment

\section{Introduction}

Since the World Health Organization (WHO) announced the 2019 novel coronavirus disease (COVID-19) as a pandemic in March 2020, human wellbeing has been threatened at a global scale as COVID-19 is perceived as a severe health crisis encountered at the beginning of this millennium [1]. The pandemic's outbreak has not only affected global health; it has also brought about detrimental effects on the energy sector [2]. Containment policies and initiatives to curb the pandemic have imposed strict measures on various aspects of life and have also included power plants, which are responsible for providing society with a continuous power supply. These measures have affected power production station workers, who are considered critical to the power production sector in maintaining a safe and reliable energy supply for consumers [3,4]. Based on reports from operators and regulators via the International Atomic Energy Agency (IAEA), Operational Experience Network (OPEX), and the International Reporting System (IRS) for operating experience, the pandemic has impacted power plants' operators and workers worldwide, for example, interrupting scheduled maintenance times and leading to concerns about worker safety and security. These factors have led to daily losses in fields of energy production and maintenance [5].

The electricity sector's challenges arising due to the pandemic extend from issues with power plant facilities and supply chains, to workers and energy management and policies [6]. For example, in the United States (US), the utilization of electricity on 27 March 2020 was 3\% lower in comparison to the amount used on the same period on 27 March 2019; this disparity signifies a loss in sales growth of approximately three years [7,8]. Therefore, it is crucial for policymakers and power system operators to adopt a scientific approach toward understanding and forecasting the ongoing effects of COVID-19 as a sector-wide undertaking. With the intention to understand the pandemic's impact on electricity production, this study examined a case study of one of Iraq's most important power plants. Our research intends to ensure the reliability of the conceptual framework chosen to assist power production stations when faced with consequences stemming from interruptions to service such as those caused by the pandemic. The proposed model was designed to help power plants make improvements to energy management and human performance during the COVID-19 pandemic.

With the aim of analyzing COVID-19's impact on the energy sector's global production, and using a conceptual model to assist the electricity sector face the pandemic's aftermath, this paper seeks to answer the following questions: 1) What are the effects of COVID-19 on the electricity sector's production? and 2) How can the power sector reduce the impacts of the pandemic? This paper also aims to strengthen and fill literary gaps about COVID-19 and the electricity sector in two ways: first, by developing a model to assist the electricity production sector mitigate the effects of the pandemic, by and understanding factors associated with employee performance and energy management. Second, we propose to provide an in-depth investigation on the pandemic's impact on the electricity sector's global production and consumption, the findings of which may 
be of use to researchers in understanding the extent to which the energy sector has been affected by the COVID-19 pandemic.

\section{Methodology}

This study seeks to analyze the impact of the COVID-19 pandemic on electricity sector production using a conceptual model and provide recommendations to assist in the sector-wide alleviation of these effects and preparation for a possible new surge. Working with a noted scarcity of available and reliable data, this work presents and classifies direct and indirect effects of the pandemic on total electricity sector production. Data was collected from direct correspondence, specialized, and official governmental and non-governmental websites from different countries and from specific case studies. The authors also surveyed the extant body of relevant theoretical literature, extracting data from reliable resources such as ScienceDirect, IEEE, and Web of Science.

To identify a method that would help to reduce the pandemic's deleterious effects manifested across the energy sector, we narrowed the focus of our practical approach to a case study in Iraq, one of the first Arab countries affected by COVID-19, and a country whose electricity sector presently struggles to meet its growing population's demand. Hence, Iraq's electricity sector provides an ideal environment for this investigation. To enhance the paper's reliability, we used a two-way approach, engaging with specialized energy experts (engineers and technicians) at Iraqi power plants and procuring supplemental data from official governmental institutions. The pandemic's possible effects on energy production and the environment were discussed, and recommendations were provided to motivate the top management and employees to improve energy performance practices in order to manage the pandemic's aftermath positively. Fig. 1 presents a flow chart explaining the study's general methodological framework.

\subsection{Analysis of the Impact of the COVID-19 Pandemic on the Electricity Production Sector}

The electric production sector, like other industrial sectors, has been affected by COVID19 in two ways. First, direct effect is the pandemic's impact on power plants' human resources: the transmission of the virus to employees has caused widespread illness and fatalities within the sector [9]. Although power plant workers are required to adhere to physical distancing and other appropriate precautionary health measures implemented by higher management for personnel safety, these protocols tend to weaken power plant management systems. According to the monthly electricity statistics report from the Organization for Economic Co-operation and Development (OECD), released in March 2020, electricity production significantly decreased in comparison with the amount of power produced between the first quarter (Q1) of 2019 and 2020 [10]. Second, indirect effect of the pandemic has been an economic one. Supply chains, electricity sales, and the reliability of power systems [11,12] have all experienced pressures as a result of low rates or delays of payment or delays in paying electricity bills, which has, for example, influenced investors' decisions to invest in the electricity sector.

\subsubsection{Analysis of Electricity Production During COVID-19 in America and Canada}

America has seen fluctuations in electricity production during the COVID-19 pandemic and, as a result, has seen significant decreases in average electricity production compared to 2019 levels of production. When viewed separately, energy sources appear to have experienced the pandemic differently: electricity generated by renewable energy sources has not been as severely affected as that generated from non-renewable power sources. Conventional thermal energy (coal) was affected the most over this time, with a significant reduction of $-33.1 \%$ compared with production from 
the previous year (181.40 TWh in 2020 to $271.40 \mathrm{TWh}$ in 2019). Electricity derived from nuclear power in Canada in the first quarter of 2020 , by contrast, grew $8.6 \%$ to 25.7 TWh compared to the same period in 2019. Thermal production in 2020 decreased by $10.4 \%$ from $37.70 \mathrm{TWh}$ in 2019 to $33.80 \mathrm{TWh}$ in 2020 in America's [13,14]. Fig. 2 illustrates this fluctuation of power production in America between the first quarter of 2019 and 2020.

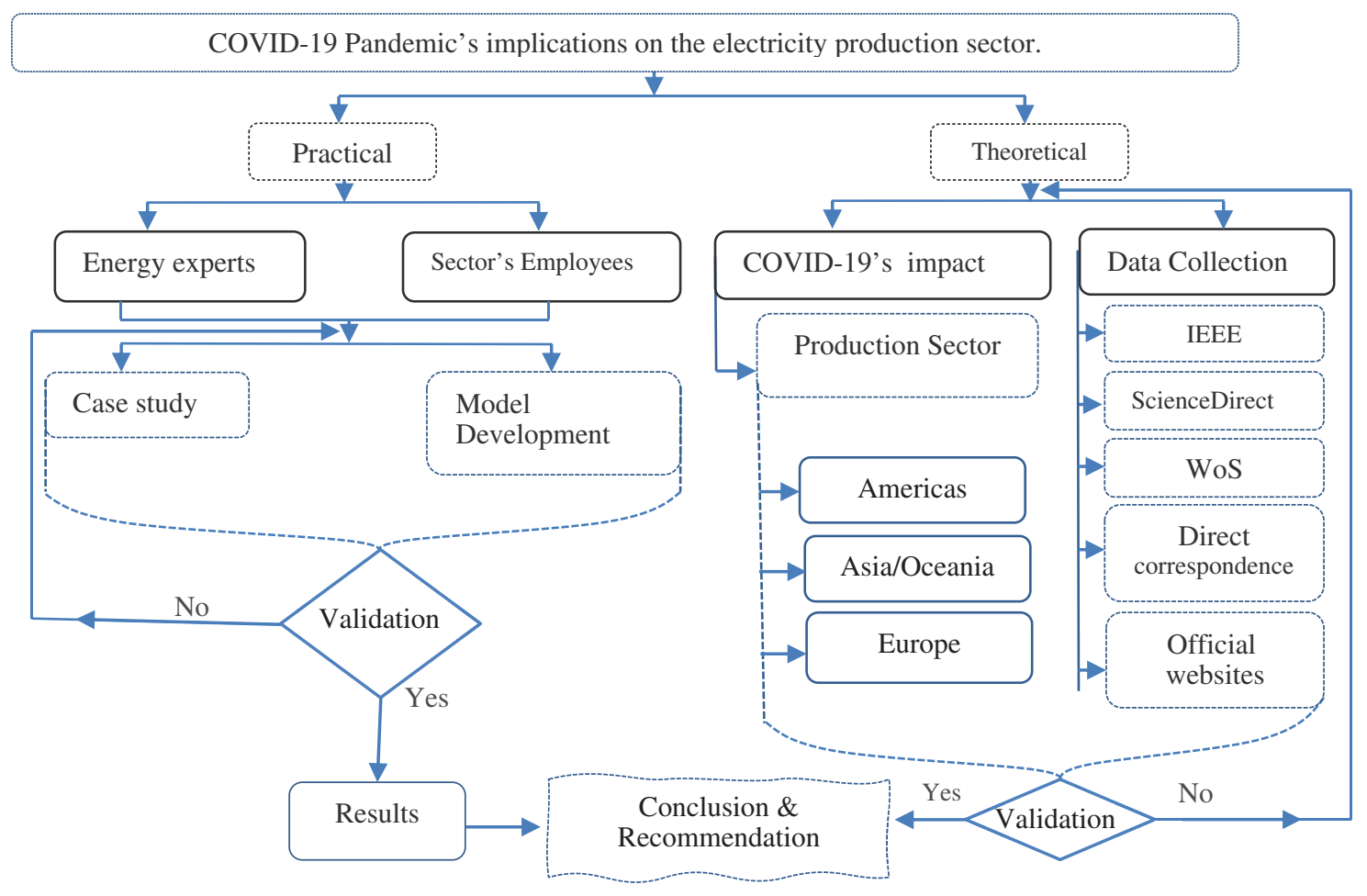

Figure 1: Research process flowchart

\subsubsection{Analysis of Electricity Production in Asia and Oceania}

Asia's electricity production has also been affected by the COVID-19 pandemic; total production declined by $3.3 \%$ in 2020 compared with the first quarter of 2019 . The most affected energy production sources in Asia have been thermal especially oil-based production, which decreased by $42.6 \%$ in 2020 compared to the first quarter of 2019. By contrast, renewable energy sources witnessed an apparent growth across the Asian continent. Production of electricity from renewables grew $84.1 \%$ from 8.5 TWh in 2019 to $15.6 \mathrm{TWh}$ in 2020. Korea, for example, experienced a decrease in electricity production from coal from 14.4 TWh in the first quarter of 2019 to $9.4 \mathrm{TWh}$ in 2020. The main reason behind this decline is the Korean government's decision in March 2020 to shut down 28 coal electric power plants to reduce air pollution and shift towards a national strategy of environmentally sustainable power production [15]. Fig. 3 illustrates this fluctuation of power production in Asia and Oceania between the first quarter of 2019 and 2020.

\subsubsection{Analysis of Electricity Production in Europe}

According to OECD, Europe's electricity production in the first quarter of 2020 totalled 297.3 TWh, 2.5\% lower than production values during the same period in 2019. During the same time, 
however, hydroelectric production increased to $19.8 \%$, which is higher than the proportion of energy production in 2019 [16].

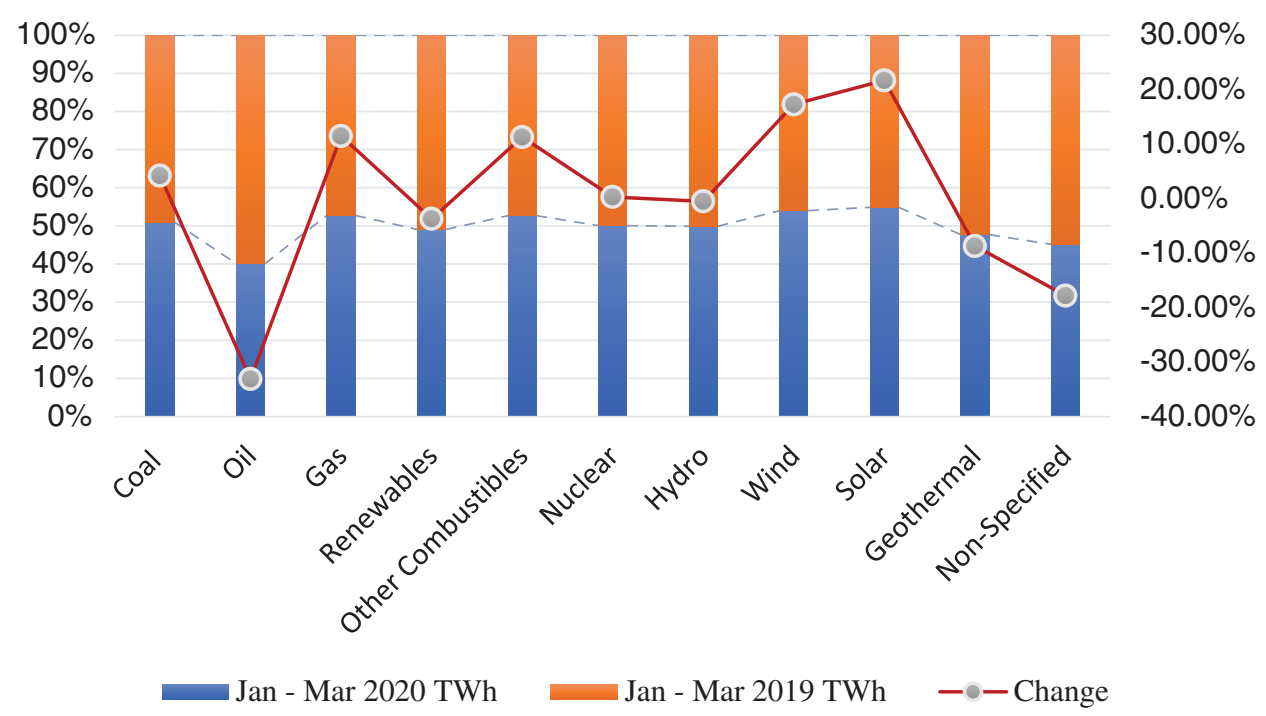

Figure 2: Fluctuate electrical energy production in America

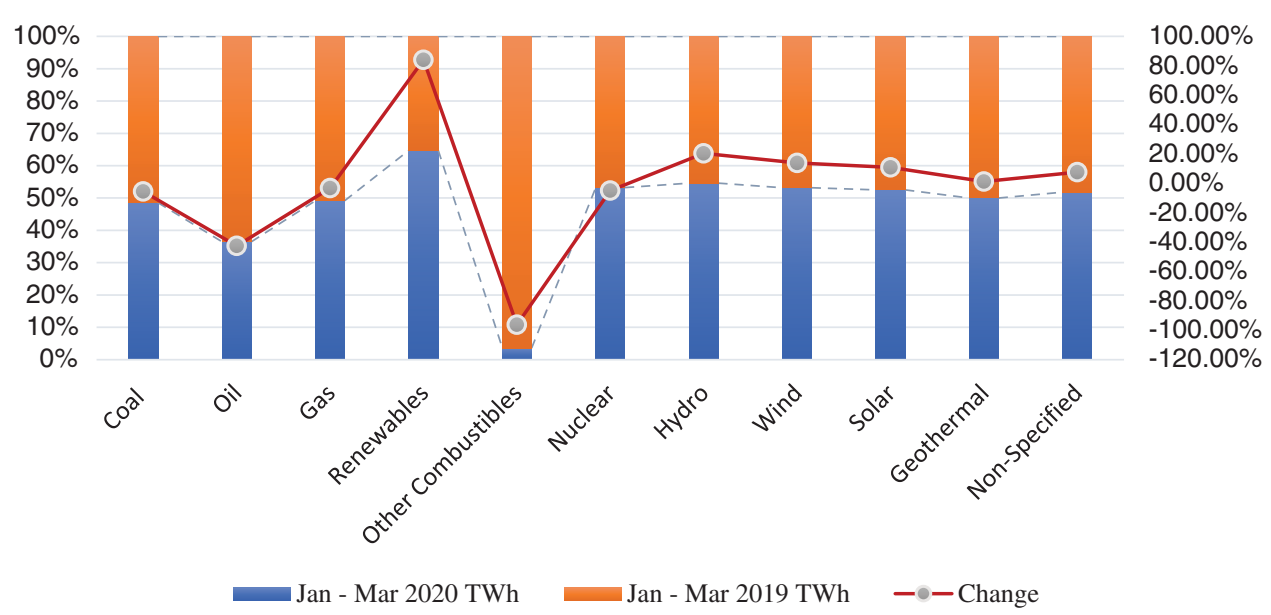

Figure 3: Fluctuate electrical energy production in Asia/Oceania

Europe also witnessed an apparent decrease of $24.2 \%$ in the amount of electricity produced using coal, followed by an $11 \%$ reduction in oil-based electricity production. The percentage of electricity produced using wind energy increased by $23.1 \%$, followed by solar power, which increased to $17 \%$, and hydroelectricity with an $11 \%$ rise in Italy; the total production decreased by $6.3 \%$ of production from 70,719 TWh in the first quarter of 2019 to $66,274 \mathrm{TWh}$ in the same period of 2020. At the same time, hydroelectric production increased by $17.5 \%$ from 7,663 TWh in the first quarter of 2019 to $9,002 \mathrm{TWh}$ in 2020 [17]. In Estonia, electricity production precipitously decreased by $50.3 \%$ in the first quarter of 2020: the amount of electricity produced 
was 1,247.8 $\mathrm{GWh}$ in comparison to 2,509 $\mathrm{GWh}$ produced in the first quarter of 2019. Estonia also witnessed a decrease in various production sources such as coal, oil, and gas by 58.7\%, while hydroelectric power recorded an increase of $145.3 \%$ over the same time. Fig. 4 indicates the difference in Europe's electricity production rates during the first quarters of 2019 and 2020.

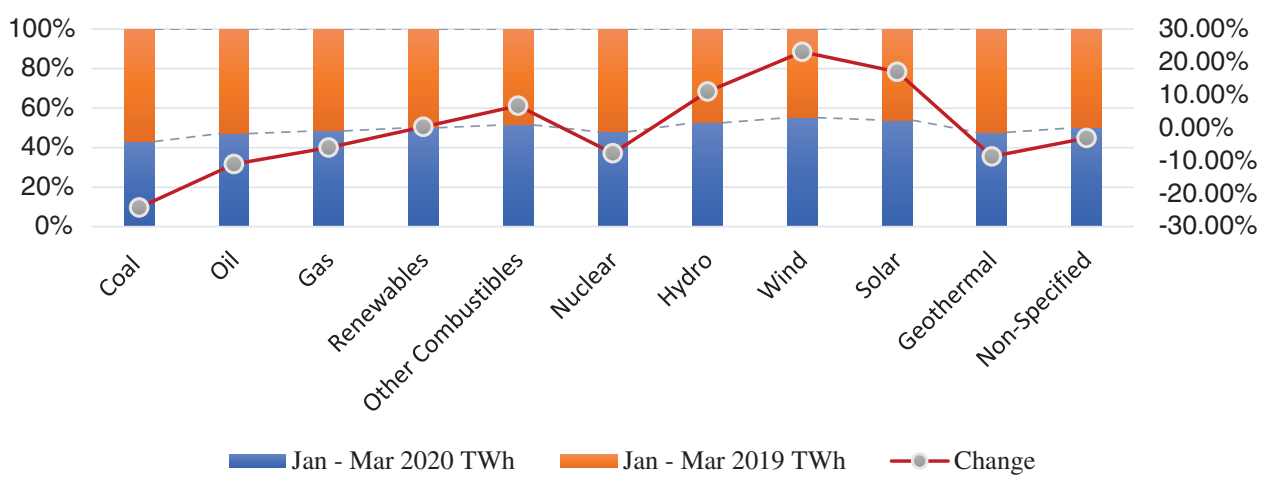

Figure 4: Europe's fluctuating electrical energy production

Net total electricity production declined by 3.3\% from 2,707.7 TWh in Q1 2019 to 2,645.0 TWh during Q1 of 2020. Fig. 5 shows these changes energy production between Q1 2020 and Q1 of 2019 [18].

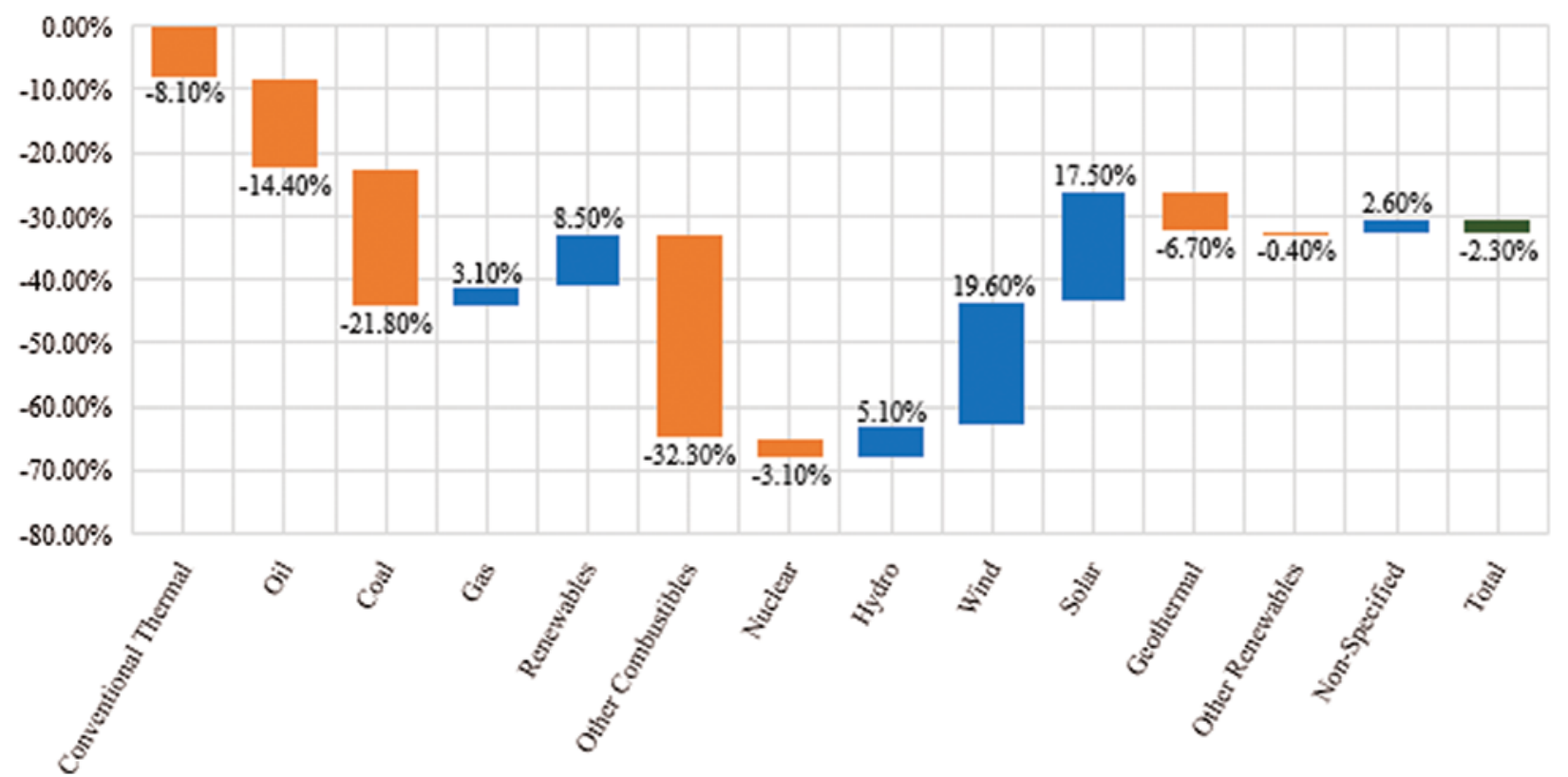

Figure 5: Changes in the production of electricity (Q1 2020 vs. Q1 2019) 


\subsection{Discussion of Implications}

We have found, from our analysis of reliable data, that the significant decrease in energy consumption rates between Q1 2019 and Q1 2020 is due to imposition of containment measures to curb the spread of COVID-19, which effectively resulted in the closure of power plants, factories, and other workplaces. However, the reduction of demand in Q1 2020 cannot be attributed entirely to COVID-19 as climatological changes also played a prominent role in the marked fluctuations in electricity production and consumption in many countries.

In the event that the demand and prices continue to decrease for an extensive duration of time, it can be expected that certain power plants will experience losses. This could expedite current tendencies of altering the situations in the sector that influence profit-gaining activities. Moreover, the ministries or departments overseeing the utilities sector may choose to postpone or revoke allowances for the building of new power plants. The development of energy demand of 2020 rely significantly on the duration, strictness and expansion of lockdowns, and swiftness of recoveries across different societies. Early assessments from the International Energy Agency (IEA) show a year-round energy of demand decrease by approximately $6 \%$, which is the same as the collective energy demand of France, Germany, Italy, and the United Kingdom in 2019. The estimated 6\% decline would be more than seven times the effect of the 2008 financial crisis on global energy consumption, which would constitute a retrogressive development of the global demand of energy over the past five years. According to the study's indicators, the demand for electricity will continue to decline due to the rise in the degree of COVID-19 infection from June 2020 onwards. If declines in demand and price persist for an extensive duration of time, setbacks to profitability (meaning significant potential losses) are likely for certain power plants. Therefore, the situation could worsen the recent patterns of volatility in the energy production industry with the potential of incurring more losses.

\section{Case Study}

To ensure a rigorous investigation, we conducted a case study on Iraq's energy production to identify appropriate methods that would help reduce the pandemic's effects on the country's electricity production sector. The process of securing reliable data required the authors to procure official approvals from the governing ministry. Due to its multiple ongoing challenges to provide sufficient energy to its growing population, all of which have intensified due to the pandemic, we considered Iraq to be an ideal subject for this study. Data needed to identify critical factors that could aid in reducing the pandemic's impact on the production sectors were collected from the related sector's personnel (energy experts and workers) through a course of online meetings.

To verify the reliability of model proposed, it was tested at the Al-Doura power plant in Baghdad, using a questionnaire adopted from the work of [19,20]. The questionnaire seeks responses to questions regarding the views of 160 respondents using a five-point Likert scale. This portion of the study adopted a descriptive research design, the existing variables from which were calculated to obtain answers to current queries pertaining to the present situation. The descriptive research design was utilized due to its capacity to offer an instant comparative analysis of the present [21]. It should be noted the number of samples obtained for this study was limited due to the pandemic; power plant employees' workdays were reduced to reinforce physical distancing and other personnel safety measures. 


\subsection{Developing a Conceptual Model to Help Power Plants}

To help further avoid the risk of COVID-19 spreading throughout energy sector production facilities, this study proposes a framework to enhance power plant energy management and the performance of their human resources. The conceptual model links the study's variables and presented relationship and direction among many different factors related to the study.

The performance in the power plants are key in these stations as they have a direct role in the control rooms, or through monitoring turbine units. Workers are tasked with performing scheduled maintenance for power stations as well as fulfilling the main responsibilities during emergencies. Therefore, measuring the effects of the COVID-19 pandemic on performance is important to future discussions of improving energy management and human performance. Subsequently, these mentioned aspects assist the higher departments in the stations to make good decisions to protect workers from becoming infected and further spreading the disease. To increase our study's reliability, we propose a conceptual framework to helping power plants to face COVID-19-related challenges. The framework was then tested and analyzed in a sample power plant in Baghdad. The association between energy management (EM) and human performance (HP) with COVID-19 in a power plant can be predicted (see Fig. 6). A conceptual framework was implemented to study the independent variables (IV) affecting EM (ISO 50001) and HP as a dependent variable (DV). The framework examines the relationship between the pandemic, as a moderator, with the IVs and DV.

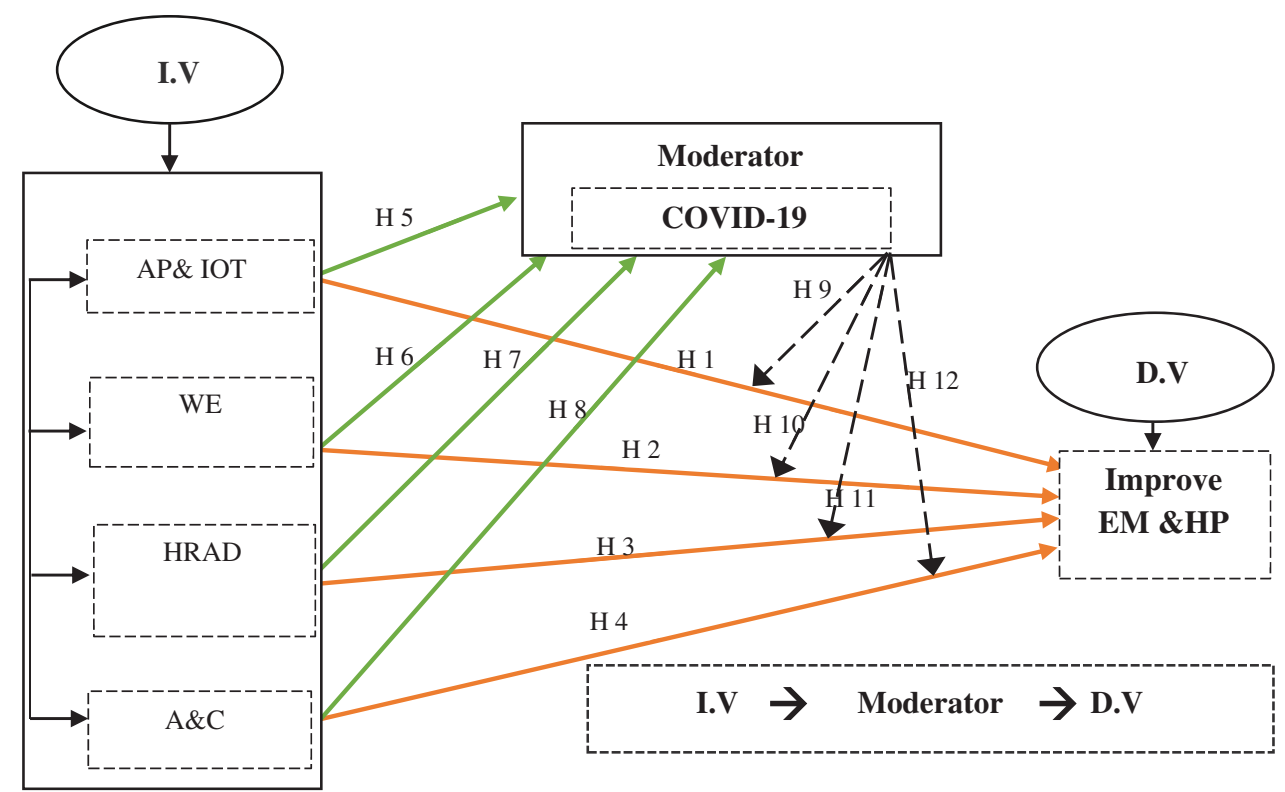

Figure 6: A Conceptual framework model to help power plants to reduce the effects COVID-19

Through the investigation and the researchers' more than 15 years of experience in the field of electric energy production, a set of factors, which have been improved, could mitigate the effects of COVID-19 on the stations. The selected independent variables (I.V) factors are: 


\subsubsection{Automation Procedures and Internet of Things ( AP \& IoT)}

Automation procedures (AP) refer to the adoption of automation procedures and the internet of things (IoT) in the power plants without the need to assign human operators in a face-toface situation, especially in the operations department (the department responsible for operating and monitoring work at the station). The departments can submit a list of identified deficits through an automation system. In addition, the automated operating system performs actions that are normally carried out manually [22,23]. Adopting this system of task automation benefits the power plant by helping prevent the occurrence of human error during manual operations. Furthermore, automation ensures that the physical distancing policy can be implemented on the premises, helping to prevent the spread of infection among power station employees [24].

\subsubsection{Workplace Environment Management (WE)}

Workplace environment refers to a working area's physical conditions, such as temperature, humidity, and ventilation [25]. The factor of WE refer to the maintenance of physical distancing and site upkeep, for example, with adequate ventilation and the provision of hand sanitizer in the workplace. The implementation of physical distancing procedures is categorized as a standard operating procedure (SOP) of the pandemic lockdown and has been universally adopted to restrict human interaction at close proximities [26,27]. The results of numerous studies have shown that social distancing has greatly contributed to reductions in the risk of COVID-19 infection [28,29].

\subsubsection{Health Risk Analysis Division (HRAD)}

The pandemic has brought up many global challenges in the industrial sector, especially the electricity production sector. Efforts to curb the spread of the infection have led to the necessity of the establishment of a unit tasked to analyze potential health risks in workplace and find appropriate ways to reduce or confront these risks. Although health programs are common in workplaces, employees may overlook their importance. Therefore, employees should be made aware of these programs' existence to improving factors productivity at work [30]. An analysis of workplace risks and assessment studies were performed with the intention of hindering occurrences of occupational hazards and ailments and therefore mitigate production losses and prevent injury to the reputation of the company itself [31,32].

\subsubsection{Awareness and Communication $(A \& C)$}

It is important for higher management to maintain worker awareness and communication on the contagious nature and detrimental effects of COVID-19 to ensure worker safety and to preserve stable energy production rates. Increasing awareness can improve worker safety and decrease the number of infections originating at the workplace. Certain approaches have been identified in evaluating at-risk behaviors termed practicing safe behaviors at the workplace [33,34]. Recently, the quantification method, which has garnered the interest of many academics due to the emergence of the need of an agile and dynamic access control system [35], was used to access control for risk-awareness, and focuses on evaluating and employing suitable measures based on levels of risks and lower thermal comfort. A higher value indicates a higher risk of employees performing incorrect procedures, and hence increases the probabilities of human error and unreliability. 


\subsection{Results of the Case Study}

\subsubsection{Reliability Analysis}

Reliability analysis measures were used to assess the questionnaire reliability and the stability of the participants' answers, in addition to the data obtained for the research to be substantial. The reason for executing a reliability quality test is ensuring that the observed variables measure the questionnaire's high error. The reliability analysis pilot study was conducted using statistical software (SPSS V16.0) and utilized Cronbach's alpha, a measure used to determine questionnaire stability and consistency. The tabulated output based on Cronbach's alpha values is shown in Tab. 1.

Cronbach's alpha coefficients shown that the questionnaire suggests a significant degree of reliability. Through the implementation of the reliability analysis of Cronbach's alpha values, the overall independent and dependent variables were assessed to gauge their reliability. In instances in which the reliabilities were less than 0.5 , they were deemed inferior and the questions are then deemed to be less reliable. Hence, Cronbach's alpha coefficient values 0.7 and above are deemed acceptably reliable.

Table 1: Reliability output analysis

\begin{tabular}{ll}
\hline Factors & Cronbach's alpha \\
\hline AP \& IOT & 0.87 \\
WE & 0.712 \\
HRAD & 0.797 \\
A \& C & 0.89 \\
EM \& HP & 0.70 \\
\hline
\end{tabular}

\subsubsection{Regression Analysis}

The regression in Tab. 2 indicates important levels of change and variance for the hypotheses. A regression analysis was performed to investigate the integration of the proposed hypotheses. Accordingly, the following 12 hypotheses were evaluated.

Hypothesis 1: The regression outcomes illustrate that the automation procedures and internet of things are negatively and significantly linked with improved energy management and human performance $[\beta$ for $\mathrm{H} 1=-0.434, \mathrm{p}<0.01]$. The first hypothesis is accepted at a $99.56 \%$ confidence level.

Hypothesis 2: Work environment management is negatively and significantly associated with energy management and human performance $[\beta$ for $\mathrm{H} 2=-0.422, \mathrm{p}<0.01]$. The second hypothesis is accepted at a $99.57 \%$ confidence level.

Hypothesis 3: Health risk analysis division is negatively and significantly associated with improved energy management and human performance $[\beta$ for $\mathrm{H} 3=-0.257, \mathrm{p}<0.01]$. The third hypothesis is accepted at a $99.74 \%$ confidence level.

Hypothesis 4: Awareness and communication is negatively and significantly associated with improved energy management and human performance $[\beta$ for $\mathrm{H} 4=-0.386, \mathrm{p}<0.01]$. The fourth hypothesis is accepted at a $99.61 \%$ confidence level. 
Hypothesis 5: Regression results indicated that automation procedures and the internet of things are positively and significantly related to COVID-19 $[\beta$ for $\mathrm{H} 5=0.288, \mathrm{p}<0.001]$. The fifth hypothesis is accepted at a $99.7 \%$ confidence level.

Hypothesis 6: Work environment management is connected positively and significantly with COVID-19 $[\beta$ for $\mathrm{H} 6=0.288, \mathrm{p}<0.001]$. The sixth hypothesis is accepted at a $99.7 \%$ confidence level.

Hypothesis 7: Health risk analysis division is connected positively and significantly with COVID-19 $[\beta$ for $\mathrm{H} 7=0.135, \mathrm{p}<0.05]$. The seventh hypothesis is accepted at a $95 \%$ confidence level.

Hypothesis 8: Awareness and communication is connected positively and significantly with COVID-19 $[\beta$ for $\mathrm{H} 8=0.196, \mathrm{p}<0.01]$. The eighth hypothesis is accepted at a $99.8 \%$ confidence level.

Hypothesis 9: From Tab. 2, the COVID-19 as a moderator of the relationship between automation procedures and the internet of things and improved energy management and human performance $[\beta$ for $\mathrm{H} 9=-0.228, \mathrm{p}<0.01]$. The ninth hypothesis is accepted at a $99 \%$ confidence level.

Table 2: Results of regression analysis

\begin{tabular}{lllllll}
\hline (I.V) & COVID-19 & \multicolumn{3}{c}{ EM \& HP } & \multicolumn{2}{c}{ COVID-19X EM \& HP } \\
\hline AP \& IOT & $\beta$ & 5 th $\mathrm{H}$ & $\beta$ & 1 st $\mathrm{H}$ & $\beta$ & 9 th H \\
& & 0.288 & & -0.434 & & -0.228 \\
& R Square & 0.122 & R Square & 0.111 & R Square & 0.032 \\
& Std. Error & 0.353 & Std. Error & 0.489 & Std. Error & 0.931 \\
WE & Sig & 0.000 & Sig & 0.000 & Sig & 0.001 \\
& $\beta$ & 6 th H & $\beta$ & 2 nd H & $\beta$ & 10 th H \\
& & 0.288 & & -0.422 & & -0.205 \\
& R Square & 0.083 & R Square & 0.107 & R Square & 0.014 \\
& Std. Error & 0.561 & Std. Error & 0.491 & Std. Error & 0.039 \\
HRAD & Sig & 0.000 & Sig & 0.000 & Sig & 0.002 \\
& $\beta$ & 7 th H & $\beta$ & 3 rd H & $\beta$ & 11 th H \\
& & 0.135 & & -0.257 & & -0.187 \\
& R Square & 0.002 & R Square & 0.048 & R Square & 0.00 \\
& Std. Error & 0.972 & Std. Error & 0.506 & Std. Error & 0.032 \\
A \& C & Sig & 0.042 & Sig & 0.000 & Sig & 0.006 \\
& $\beta$ & 8 th H & $\beta$ & 4 th H & $\beta$ & 12 th H \\
& & 0.196 & & -0.386 & & -0.198 \\
& R Square & 0.126 & R & 0.090 & R Square & 0.042 \\
& Std. Error & 0.331 & Std. Error & 0.495 & Std. Error & 0.35 \\
& Sig & 0.003 & Sig & 0.000 & Sig & 0.003 \\
\hline
\end{tabular}

Hypothesis 10: COVID-19 as a moderator of the relationship between work environment with improved energy management and human performance $[\beta$ for $\mathrm{H} 10=-0.205, \mathrm{p}<0.01]$. The tenth hypothesis is accepted at a $99 \%$ confidence level. 
Hypothesis 11: COVID-19 as a moderator of the relationship between health risk analysis division and improved energy management and human performance $[\beta$ for $\mathrm{H} 11=-0.187, \mathrm{p}<$ 0.01]. The eleventh hypothesis is accepted at a $99 \%$ confidence level.

Hypothesis 12: COVID-19 as a moderator of the relationship between awareness and communication improved energy management and human performance $[\beta$ for $\mathrm{H} 12=-0.198, \mathrm{p}<0.01]$. The twelfth hypothesis is accepted at a $99 \%$ confidence level.

From these results, we can suggest that this histogram of factors, AP, IoT, WE, HRAD, and AC are significantly related to COVID-19, based on the frequent distribution. The histograms of these results are normally distributed, as shown in Fig. 7.
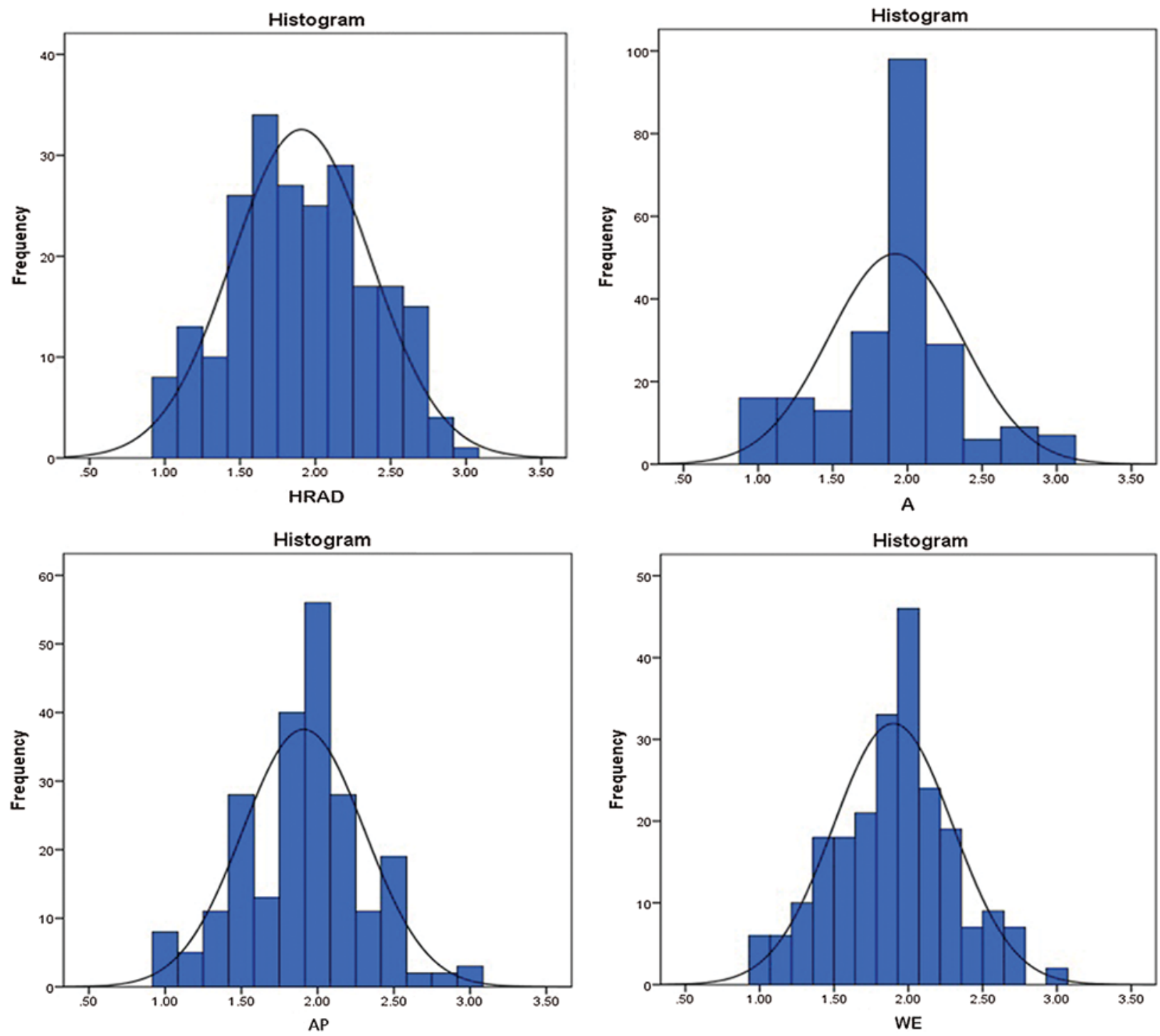

Figure 7: Histogram results 


\section{Conclusion and Recommendation}

The consequences of the COVID-19 pandemic have adversely impacted the world economically, socially, technologically, and politically at a colossal scale, causing significant losses in the time since it began. The pandemic has affected not only human wellbeing but also areas of energy generation, the primary topic of focus of the research presented in this paper [36]. The results of this study show that the factors such as IoT and awareness with communication represent a significant percentage of the survey respondents' attention, with Cronbach's alpha of 0.87 for IoT and 0.89 for AC. Therefore, these numbers are considered dangerous indicators as the measured factors can affect performance and energy management and should not be overlooked by a power generating plant's upper management. Energy management and workers' performance at a power production facility can be improved by enhancing working conditions and providing a healthy and safe work environment, which allow for the maintenance of stable rates of production, while also ensuring continued job satisfaction, especially under the exigent circumstances of the ongoing COVID-19 pandemic. This study provides first-hand, systematic information on how the COVID-19 pandemic has impacted energy generation as a global phenomenon and makes use of several assumptions and scientific scenarios to address challenges specific to the pandemic that have arisen in the energy sector. This study also provides a conceptual framework based on a case study carried out at the Al-Doura electric power production plant in Baghdad, Iraq. This case study was conducted to understand and effectively contend with challenges caused by the pandemic, specifically to improve energy management and the performance of human resources at power plants. This study's proposed model determined specific factors that directly affect such energy management and human performance. We also designed a framework to measure the effects of COVID-19 as a moderator on the improvement of the dependent variables, i.e., energy management and human performance, as well as the independent variables. The results showed that demographic variables have a significant effect on COVID-19 in power plants. The case study's model provided the tools needed to investigate and analyze 12 unique research hypotheses.

The results of this study clarify specific ways in which COVID-19 influences energy management and human performance at power stations. From the regression analysis shown in Tab. 2, the 12 hypotheses in this research are statistically acceptable, supported, and significant at high levels of confidence. The hypotheses all help explain the direct and moderation relationships between the identified variables. This research also discussed the similarity between the different kinds of data reviewed and found that most of the respondents to the questionnaire preferred the model to help them make positive decisions. A successful, pragmatic, and correct on-time decision, in this sense, could lead the organizations toward successfully stabilizing worker performance even in the face of such environmental disruptions. The regression and moderation analysis results also reveal significant correlations between the independent, dependent, and moderation variables. This study was conducted to confirm previous empirical studies founded on the part played by the COVID-19 pandemic on energy management and human performance. The findings are therefore useful as they will assist power stations in improving their energy management and performance of human resources through appropriate measures in addressing challenges arising due to the pandemic.

Presuming the pandemic is contained (confined and controlled) within Q1 of 2021, it is possible to revive the energy generation sector within Q3 of 2021. However, if the pandemic's containment follows a protracted path, the revival process will necessarily take longer due to shortfalls in funding or a cash crunch scenario. The possibility of companies winding back, however, may lead to a cascading effect. The fastest revival is possible if governments provide strong stimuli for this sector, which is likely because of the energy sector's importance to all 
aspects of a modern, functioning society. We conclude with twelve important recommendations for future prospective work in this field of study:

(i) Using different methodologies, processes, and approaches, future research should continue to explore how a pandemic affects various sectors.

(ii) The proposed framework can be implemented and assessed in serving and assisting all sectors of energy, such as transportation and distribution.

(iii) The proposed framework can be employed in the event of an outbreak of any subsequent coronavirus mutation or other novel viruses that may emerge in the future. Findings from the case study discovered that the Iraqi power plants in question have yet to adopt and implement ISO 50001 and EMs due to obstacles coming from top management and organization culture either mediator or moderator in addition to the absence of maintenance culture as a mediator or moderator and the integration of the factors of success and the non-integration between performance, work environment and energy management practices, this study recommends providing a framework of CSFs for performance are integrated with the workplace environment and EMs to facilitating energy management adoption and improving performance at Iraqi power plants.

(iv) Through the answers of the respondents and the interview with managers in Iraqi power plants, there are difficulty adopting ISO 50001 and EMs in Iraqi power plants and it has not been implemented yet, and increased cases of failure and problems due to human errors resulting from neglect of human factors and the work environment with energy management in the maintenance of Iraqi power plants. Therefore, we recommend conducting further research into critical success factors to facilitate the adoption of energy management and to improve the performance of workers in Iraqi power plants.

(v) Through this study, it can be concluded that producing electricity using renewable energy sources is highly stable and reliable. Therefore, we recommended supporting the generation of electricity using renewable energy sources.

(vi) Power plants need more integration between energy management and ISO 50001 with quality management, specifically quality service. On the other hand, integration between performance and workplace environment (ergonomics) is necessary.

(vii) Power production plants need to be researched more, and critical success factors for energy management should be integrated with critical success factors for quality, including quality service.

We also recommend that more research be carried out to investigate the integration of performance success factors and work environment success factors to overcome poor performance in power plants.

(viii) From the results of our analysis of the case study, we recommend digitizing the electricity sector along with the production sector. The digitization process can also include distribution and transmission to ensure safe operations in all changing circumstances.

(ix) The researchers did not find studies investigating critical success factors for performance (human factors and human error), in the workplace environment (ergonomics) or facilitating the adoption of energy management ISO 50001 with quality management, specifically quality service. Therefore, we recommend further research to overcome current risks faced by power plants.

(x) Based on the respondents' responses in the questionnaire, more attention should be given to implementation of the internet of things (IoT) and awareness with communication (AC) in power plants. 
(xi) This paper recommends more investigation on the role of top management in the adoption of energy management standard ISO 50001 in power plants with CSFs. This may facilitate the adoption of better energy policies, cost reduction, environmental impact, and lead to improvements in service quality and energy savings.

(xii) The study suggests that top power plants' management should consider the use of alternative fuels to ensure the electricity production system's stability.

Acknowledgement: Foremost, the authors express their sincere gratitude to Universiti Teknologi Malaysia (UTM)/Razak Faculty of Technology and Informatics for providing financial support. Furthermore, the authors are incredibly grateful to the Iraqi Ministry of electricity for providing the necessary data.

Funding Statement: This work is supported by the Universiti Teknologi Malaysia under Research University Grants Q.K130000.3556.07G32 and Q.K130000.3556.06G45 for the financial support provided throughout the course of this research project.

Conflicts of Interest: The authors declare that they have no conflicts of interest to report regarding the present study.

\section{References}

[1] C. Sohrabi, Z. Alsafi, N. O'Neill, M. Khan, A. Kerwan et al., "World health organization declares global emergency: A review of the 2019 novel coronavirus (COVID-19)," International Journal of Surgery, vol. 76, no. 2, pp. 71-76, 2020.

[2] S. Cheval, C. Mihai Adamescu, T. Georgiadis, M. Herrnegger, A. Piticar et al., "Observed and potential impacts of the COVID-19 pandemic on the environment," International Journal of Environmental Research and Public Health, vol. 17, no. 11, pp. 4140, 2020.

[3] M. Mofijur, I. M. R. Fattah, M. A. Alam, A. B. M. S. Islam, C. Ong et al., "Impact of COVID-19 on the social, economic, environmental and energy domains: Lessons learnt from a global pandemic," Sustainable Production and Consumption, vol. 26, pp. 343-359, 2021.

[4] W. Scheidel, "The Coronavirus pandemic and the future of economic inequality," Social Research: An International Quarterly, vol. 87, no. 2, pp. 293-295, 2020.

[5] R. Madurai Elavarasan, G. M. Shafiullah, K. Raju, V. Mudgal, M. T. Arif et al., "COVID-19: Impact analysis and recommendations for power sector operation," Applied Energy, vol. 279, pp. 115739, 2020.

[6] S. E. Hosseini, "An outlook on the global development of renewable and sustainable energy at the time of COVID-19," Energy Research \& Social Science, vol. 68, no. 4, pp. 101633, 2020.

[7] R. Patil, U. Patel and T. Sarkar, "COVID-19 cases prediction using regression and novel SSM model for non-converged countries," Journal of Applied Science, Engineering, Technology, and Education, vol. 3, no. 1, pp. 74-81, 2021.

[8] G. Ruan, D. Wu, X. Zheng, H. Zhong, C. Kang et al., "A cross-domain approach to analyzing the short-run impact of COVID-19 on the US electricity sector," Joule, vol. 4, no. 11, pp. 2322-2337, 2020.

[9] N. Vindegaard and M. E. Benros, "COVID-19 pandemic and mental health consequences: Systematic review of the current evidence," Brain Behavior, and Immunity, vol. 89, pp. 531-542, 2020.

[10] A. J. Prime, "Report monthly electricity statistics," International Energy Agency, vol. 1, no. 9, pp. 168, 2020.

[11] R. W. Houldin and B. Yang, "Going viral: The impacts of covid19 on retail electricity," The Electricity Journal, vol. 34, no. 2, pp. 106903, 2021.

[12] C. W. Craighead, D. J. Ketchen Jr and J. L. Darby, "Pandemics and supply chain management research: Toward a theoretical toolbox," Decision Sciences, vol. 51, no. 4, pp. 838-866, 2020. 
[13] L. Adua, "Reviewing the complexity of energy behavior: Technologies, analytical traditions, and household energy consumption data in the United States," Energy Research \& Social Science, vol. 59, no. 2, pp. 101289, 2020.

[14] D. Agdas and P. Barooah, "Impact of the COVID-19 pandemic on the US electricity demand and supply: An early view from data," IEEE Access, vol. 8, pp. 151523-151534, 2020.

[15] Mathilde and Julian, "Report monthly electricity statistics," International Energy Agency, vol. 12, no. 3, pp. 1-65, 2020.

[16] A. Bahmanyar, A. Estebsari and D. Ernst, "The impact of different COVID-19 containment measures on electricity consumption in Europe," Energy Research \& Social Science, vol. 68, pp. 101683, 2020.

[17] N. Safari, G. Price and C. Y. Chung, "Comprehensive assessment of COVID-19 impact on Saskatchewan power system operations," IET Generation Transmission \& Distribution, vol. 15, no. 1, pp. 164-175, 2021.

[18] H. Zhong, Z. Tan, Y. He, L. Xie and C. Kang, "Implications of COVID-19 for the electricity industry: A comprehensive review," Journal of Power and Energy Systems, vol. 6, no. 3, pp. 489-495, 2020.

[19] A. A. Ajmi, N. S. Mahmood and S. R. Kamat, "Increase the performance of power station: Results and analysis of an empirical study of the ISO 50001 energy management systems in the Iraqi ministry of electricity," Magnt Research Report, vol. 4, no. 2, pp. 75-86, 2017.

[20] S. A. R. Shah, K. R. Jamaludin and H. H. A. Talib, "Integrated quality environmental management implementation in food processing SMEs," The TQM Journal, vol. 31, no. 5, pp. 740-757, 2019.

[21] J. Bloomfield and M. J. Fisher, "Quantitative research design," Journal of the Australasian Rehabilitation Nurses Association, vol. 22, no. 2, pp. 27-30, 2019.

[22] S. J. Lee and P. H. Seong, "Development of automated operating procedure system using fuzzy colored petri nets for nuclear power plants," Annals of Nuclear Energy, vol. 31, no. 8, pp. 849-869, 2004.

[23] C. J. Lin, T. Yenn and W. Yang, "Automation design in advanced control rooms of the modernized nuclear power plants," Safety Science, vol. 48, no. 1, pp. 63-71, 2010.

[24] F. Civerchia, S. Bocchino, C. Salvadori, E. Rossi, L. Maggiani et al., "Industrial internet of things monitoring solution for advanced predictive maintenance applications," Journal of Industrial Information Integration, vol. 7, no. 3, pp. 4-12, 2017.

[25] A. Ali, N. Mahmood, K. R. Jamaludin, H. H. A. Talib, S. Sarip et al., "An efficient framework for identifying current open issues to prevent human errors in maintaining power plants: Research gap," in Materials Science and Engineering, Materials Today: Proc., India, 2021.

[26] T. P. B. Thu, P. N. H. Ngoc and N. M. Hai, "Effect of the social distancing measures on the spread of COVID-19 in 10 highly infected countries," Science of the Total Environment, vol. 742, no. 92, pp. 140430, 2020.

[27] N. S. Mahmood, A. A. Ahmed, S. Shamsul, H. M. Kaidi, R. J. Khairur et al., "Energy management cultures assessment and its impact on the quality of service in power plants a research gap for future studies," PalArch's Journal, vol. 17, no. 7, pp. 16, 2020.

[28] D. IbarraVega, "Lockdown, one, two, none, or smart. modeling containing covid-19 infection. A conceptual model," Science of the Total Environment, vol. 730, no. 2, pp. 138917, 2020.

[29] Q. Lin, S. Zhao, D. Gao, Y. Lou, S. Yang et al., "A conceptual model for the coronavirus disease 2019 (COVID-19) outbreak in Wuhan, China with individual reaction and governmental action," International Journal of Infectious Diseases, vol. 93, no. 1766, pp. 211-216, 2020.

[30] P. Dangol, "An analysis of factors improving productivity at work," Quantitative Economics and Management Studies, vol. 1, no. 4, pp. 268-274, 2020.

[31] A. S. Ahmar, "Correlation between Covid-19 and weather/climate indicators: A Response," JINAV: Journal of Information and Visualization, vol. 1, no. 1, pp. 34-35, 2020.

[32] N. G. Mutlu and S. Altuntas, "Risk analysis for occupational safety and health in the textile industry: Integration of FMEA, FTA, and BIFPET methods," International Journal of Industrial Ergonomics, vol. 72 , no. 9, pp. 222-240, 2019. 
[33] K. Yamada, I. Yamaguchi, H. Urata and N. Hayashida, "Survey of awareness of radiation disasters among firefighters in a Japanese prefecture without nuclear power plants," PLoS ONE, vol. 15, no. 7, pp. 1-15, 2020.

[34] O. Wirth and S. O. Sigurdsson, "When workplace safety depends on behavior change: Topics for behavioral safety research," Journal of Safety Research, vol. 39, no. 6, pp. 589-598, 2008.

[35] K. Ma, G. Yang and Y. Xiang, "RCBAC: A risk-aware content-based access control model for largescale text data," Journal of Network and Computer Applications, vol. 167, no. 2, pp. 102733, 2020.

[36] M. Sherif, "The impact of Coronavirus (COVID-19) outbreak on faith-based investments: An original analysis," Journal of Behavioral and Experimental Finance, vol. 28, no. 1, pp. 100403, 2020. 